\title{
O CONCEITO DE CONTRARREVOLUÇÃO PROLONGADA DE FLORESTAN FERNANDES: ESTADO DE EXCEÇÃO NO BRASIL.
}

\author{
THE CONCEPT OF AGAINST PROLONGED REVOLUTION OF \\ FLORESTAN FERNANDES: STATE OF EXCEPTION IN BRAZIL.
}

\author{
Carlos Augusto de Oliveira Diniz ${ }^{1}$
}

Resumo: Para analisar o conceito de contrarrevolução prolongada no Brasil pautou-se pelo método dedutivo em revisão bibliográfica. Discutiu-se a relação do Estado com a propriedade e como isso impacta no direito. Abordou-se o Estado de Exceção e posteriormente o caso do Estado brasileiro com base no conceito de contrarrevolução prolongada. O objetivo geral é explicitar que o estado de exceção é regra, o específico é demonstrar que no Brasil o estado de exceção é constante e anterior ao conceito contemporâneo. Como resultado temos no Brasil nunca se teve democracia efetiva, nossa história é alternância de mais repressão e menos repressão.

Palavras-chave: Estado; Propriedade; Poder; Contrarrevolução; Democracia.

Summary: To analyze the concept prolonged counterrevolution in Brazil, it was based on the deductive method in bibliographic review. The State's relationship with property was discussed and this impacts on the law. The State of Exception discussed and later the case of the Brazilian State based on the concept of prolonged counterrevolution. The objective is explain that the state of exception is rule, the specific one is to demonstrate that in Brazil the state of exception is constant and prior to the contemporary. A result we have never effective democracy in Brazil, our history is alternation of more and less repression.

Keywords: State; Property; Power; Counter-revolution; Democracy.

\section{Introdução.}

\footnotetext{
${ }^{1}$ Doutor em Direito pela Pontifícia Universidade Católica de São Paulo (PUC-SP), Área de Concentração: Efetividade do Direito na linha de pesquisa: Ética, Linguagem e Justiça. Professor da Carreira de Magistério Superior do Curso de Direito da Universidade Federal de Goiás (UFG) - Regional Jataí-GO. Coordena o Projeto de Pesquisa "Poder, Estado e Capitalismo: Impactos no Processo de Construção do Direito (PI03572-2019)". Lattes: http://lattes.cnpq.br/3127802813505867 - E-mail: carlosaugustodiniz@hotmail.com; Endereço: Universidade Federal de Goiás - Regional Jataí / Campus Jatobá / Prédio do Curso de Direito / Gabinete 24. BR 364, Km 195, nº 3800, CEP: 75801-615, Jataí-GO.
} 
O presente trabalho se funda em uma análise do pensamento de Florestan Fernandes presente na obra A revolução burguesa no Brasil; ensaio de interpretação sociológica ${ }^{2}$. Nesse estudo Florestan Fernandes analisa aspectos do desenvolvimento capitalista no Brasil e consequentemente do desenvolvimento da burguesia brasileira. Tal classe teve seu papel histórico moldado e reduzido pelos países hegemônicos e por isso a burguesia brasileira optou por fundar-se no patrimonialismo e no escravismo.

Este texto trata-se de uma revisão bibliográfica estruturado no método dedutivo, ou seja, partiu-se de conceitos e aspectos gerais para um ponto mais específico. Durante o desenvolvimento um conceito de Florestan Fernandes revelou-se crucial, trata-se da contrarrevolução prolongada no Brasil.

O objetivo geral é inicialmente explicar fundado, sobretudo na obra de Giorgio Agamben $^{3}$ como o estado de exceção se desenvolveu e chegou ao ponto de firmar-se não como momento passageiro, mas vertendo-se em regra, ou seja, constante, ininterrupto. Principalmente em países hegemônicos como Estados Unidos, por exemplo.

Já como objetivo específico este trabalho possui a pretensão de demonstrar que no Brasil o estado de exceção é constante e anterior ao conceito contemporâneo, ou seja, muito antes da obra de Giorgio Agamben ${ }^{4}$ ganhar repercussão contemporânea mundial no Brasil o conceito de contrarrevolução prolongada de Florestan Fernandes $^{5}$ já era discutido e percebido no Brasil.

Sendo assim, no primeiro tópico será abordado o conceito crítico de Estado com o pensamento de Vladimir Ilitch Lenine na obra $O$ Estado e a Revolução ${ }^{6}$. Em segundo lugar discutir-se-á no a importância da propriedade para o Estado de Exceção, mormente sobre o aspecto de que sem a propriedade não haveria necessidade de Estado e talvez o direito sequer

\footnotetext{
${ }^{2}$ FERNANDES, Florestan. A revolução burguesa no Brasil; ensaio de interpretação sociológica. 3 ed. Rio de Janeiro: Guanabara, 1987.

${ }^{3}$ AGAMBEN, Giorgio. Estado de exceção. Tradução de Iraci D. Poleti. São Paulo: Boitempo, 2004.

${ }^{4}$ Ibidem.

${ }^{5}$ FERNANDES, 1987.

6 LENINE, Vladimir Ilitch. O Estado e a Revolução. Agosto-Setembro 1917. Disponível em: < http://pcb.org.br/portal/docs/oestadoearevolucao.pdf > Acesso em: 06 de AGO. de 2018.
} 
teria se desenvolvido nos moldes que o conhecemos. Por último temos a discussão mais específica ao exemplo brasileiro fundado especificamente na obra de Florestan Fernandes ${ }^{7}$.

Ao final chegamos a uma conclusão que necessariamente passou pelas análises acima descritas, e necessariamente passando por uma análise de nossa história e os aspectos estruturantes do Estado, burguesia, e da efetividade de nossa democracia.

\section{Estado: conceito crítico.}

Para apresentar um conceito de Estado utiliza-se a obra de Vladimir Ilitch Lenine $O$ Estado e a Revolução $o^{8}$, pois essa obra apresenta concepção importante sobre o tema. Dessa forma, o Estado é definido da seguinte forma:

É um produto da sociedade numa certa fase do seu desenvolvimento. É a confissão de que essa sociedade se embaraçou numa insolúvel contradição interna, se dividiu em antagonismos inconciliáveis de que não pode desvencilhar-se. Mas, para que essas classes antagônicas, com interesses econômicos contrários, não se entre devorassem e não devorassem a sociedade numa luta estéril, sentiu-se a necessidade de uma força que se colocasse aparentemente acima da sociedade, com o fim de atenuar o conflito nos limites da "ordem". Essa força, que sai da sociedade, ficando, porém, por cima dela e dela se afastando cada vez mais, é o Estado". ${ }^{9}$

Partindo do entendimento de que o Estado seja produto de uma sociedade em certa fase de seu desenvolvimento fica claro que o Estado não é uma constante na história, ou seja, justamente por ser uma fase pode-se concluir que se trata de uma exceção no desenvolvimento de uma sociedade. Logo, o termo Estado de exceção apresenta-se como uma redundância.

O termo exceção esvazia/esconde/ofusca o sentido de Estado conduzindo a um pensamento de que existe uma exceção que não seja o próprio Estado. Pontue-se ainda que o Estado não é um conciliador de classes, mas sim que ele só existe onde exista a contradição da luta de classes.

Para Marx, o Estado não poderia surgir nem subsistir se a conciliação das classes fosse possível. Para os professores e publicistas burgueses e para os filisteus despidos de escrúpulos, resulta, ao contrário, de citações complacentes de Marx, semeadas em profusão, que o Estado é um instrumento de conciliação das classes. Para Marx, o Estado é um órgão de dominação de classe, um órgão de submisso de uma classe por outra; é a criação de uma "ordem" que legalize e consolide essa submissão, amortecendo a colisão das classes. Para os políticos da pequena

\footnotetext{
${ }^{7}$ FERNANDES, 1987.

${ }^{8}$ LENINE, 1917.

${ }^{9}$ LENINE, 1917. p. 3.
} 
burguesia, ao contrário, a ordem é precisamente a conciliação das classes e não a submissão de uma classe por outra; atenuar a colisão significa conciliar, e não arrancar às classes oprimidas os meios e processos de luta contra os opressores a cuja derrocada elas aspiram. ${ }^{10}$

Neste sentido, o Estado é uma exceção que atua para oprimir ao contrário de conciliar, pois esta postura adotada por ele na esfera política de se manter afastado das demandas privadas de cada classe não é despretensiosa, trata-se de um ardil para ocultar a sua atuação de opressor da classe operária e com isso emitir mensagem de normalidade social quando na verdade promove a dominação para atender uma classe, burguesia.

Porém, quando essa opressão é confrontada pela classe oprimida o Estado como fase será superado como pontua Vladimir Ilitch Lenine se referindo a Revolução Russa em 1917

[...] se o Estado é o produto da inconciliabilidade das contradições de classe, se é uma força superior à sociedade, "afastando-se cada vez mais da sociedade", é claro que a libertação da classe oprimida só é possível por meio de uma revolução violenta e da supressão do aparelho governamental criado pela classe dominante e que, pela sua própria existência, "se afasta" da sociedade. ${ }^{11}$

A conciliação em si apresenta-se como um empecilho ao fluxo da história, pois procurar retirar do Estado seu aspecto de fase de uma sociedade. Isso na ilusão de que impedirá o processo histórico de acontecer. Cite-se:

"O Estado, por conseguinte, não existiu sempre. Houve sociedades que passaram
sem ele e que não tinham a menor noção de Estado nem de poder governamental. A
um certo grau do desenvolvimento econômico, implicando necessariamente na
divisão da sociedade em classes, o Estado tornou-se uma necessidade, em
conseqüência dessa divisão. Presentemente, marchamos a passos largos para um tal
desenvolvimento da produção, que a existência dessas classes não só deixou de ser
uma necessidade, como se toma mesmo um obstáculo à produção. As classes
desaparecerão tão inelutavelmente como apareceram. Ao mesmo tempo que as
classes desaparecerá inevitavelmente o Estado. A sociedade reorganizando a
produção sobre a base da associação livre e igual de todos os produtores, enviará a
máquina governamental para o lugar que lhe convém: o museu de antigüidades, ao
lado da roda de fiar e do machado de bronze.

Se de fato trata-se de uma fase pela qual passa uma sociedade em seu processo de desenvolvimento é preciso entender como ocorrerá a superação dessa etapa/fase? Tal processo requer que o proletariado assuma o Estado, para que se de o início do processo de transição

\footnotetext{
${ }^{10}$ Ibidem. p. 4.

${ }^{11}$ LENINE, 1917. p. 4.

${ }^{12}$ Ibidem. p. 8.
} 
social que promoverá simultaneamente a extinção do próprio proletariado pelo fato de que o oprimido não está mais passível de opressão. ${ }^{13}$

Isso ocorre quando a compreensão do Estado como fase e da necessidade de superar essa fase pertence a todos os trabalhadores. Se a classe trabalhadora não possuir essa compreensão amadurecida a ideia não terá chegado ao seu tempo e por isso será fraca, pois a ideia fora do tempo é frágil.

Esta compreensão não é de difícil constatação, pois nem sempre o Estado existiu, mas quando ele surgiu esteve ao lado de uma pequena parcela que sempre fez dele um instrumento de opressão e dominação, ou seja, ele sempre foi de alguém, na Antiguidade pertenceu aos proprietários de escravos; na Idade Média ele foi nobreza feudal; e em nosso tempo ele tem sido da burguesia. ${ }^{14}$ Neste rumo se a classe trabalhadora possui a ideia de revolução maturada o processo ocorrerá com vistas ao seguinte quadro

O proletariado se apodera da força do Estado e começa por transformar os meios de
produção em propriedade do Estado. Por esse meio, ele próprio se destrói como
proletariado, abole todas as distinções e antagonismos de classes e,
simultaneamente, também o Estado, como Estado. A antiga sociedade, que se movia
através dos antagonismos de classe, tinha-se necessidade do Estado, isto é, de uma
organização da classe exploradora, em cada época, para manter as suas condições
exteriores de produção e, principalmente, para manter pela força a classe explorada
nas condições de opressão exigidas pelo modo de produção existente (escravidão,
servidão, trabalho assalariado). ${ }^{15}$

Importante ainda é uma abordagem acerca da propriedade, pois não se pode deixar de abordá-la para compreender o Estado. A propriedade privada dos meios de produção é a essência de toda contradição da luta de classes e consequentemente o que impulsiona a aparição do Estado onde os antagonismos de classes são inconciliáveis. ${ }^{16}$

\section{A importância da propriedade para o Estado de Exceção.}

Para entender a propriedade e como ela é fundamento da sociedade capitalista e por consequência do Estado e do Direito recorre-se a obra de Georg Wilíelm Friedrich Hegel Princípios da filosofia do direito ${ }^{17}$ para encontrar a essência do que seja propriedade.

\footnotetext{
13 Ibidem.

${ }^{14}$ LENINE, 1917.

${ }^{15}$ LENINE, 1917. p. 8/9.

${ }^{16}$ Ibidem.

${ }^{17}$ HEGEL, Georg Wilíelm Friedrich, 1770-1831. Princípios da filosofia do direito / G.W.F. Hegel; tradução Orlando Vitorino. - São Paulo: Martins Fontes, 1997.
} 
De início é preciso estabelecer uma análise que se funde em entender o que é próprio do homem, ou seja, como entender a propriedade e sua relação como o homem, ou como este homem se relaciona com a propriedade. Por exemplo, quando se fala em direito de propriedade é possível entender: 1) direito de conservar o que lhe pertence e de apropriar-se daquilo que outrem lhe cede legalmente ou que adquire sem contestação. 2) Faculdade do proprietário de usar, gozar e dispor da coisa, e de reavê-la do poder de quem quer que injustamente a possua.

Apresentados tais pontos é importante analisar a raiz do termo propriedade que se refere à característica particular de algo, ou de alguém. Imagine-se que ser ácido/azedo é uma propriedade do limão. Neste sentido, a propriedade é algo que está contida em algo ou alguém.

É importante fazer um questionamento: Seria possível que ocorresse uma cessão/transmissão de propriedade sem que transmissor e receptor o perdessem suas essências? Logicamente que não, pois o que é próprio está contido e não será incorporado, ou seja, entendendo que essência é o objetivo de algo qualquer ato cessão/transmissão fatalmente alterará essa essência, pois se mostra um ato de apropriar algo ou alguém de uma propriedade que não é sua, ou de algo que não lhe é próprio.

Se o ato descrito de apropriar algo ou alguém de uma característica altera a essência desse algo ou alguém, o processo reverso de desapropriar também altera a essência daquele de quem se desapropria. De modo que apropriar ou desapropriar somente é possível em um mundo virtual, pois no mundo real as coisas são o contrário de deveriam ser.

E nesta abordagem sobre a propriedade destaca-se sua relação com o direito e posteriormente como o Estado. Dessa forma:

O direito começa por ser a existência imediata que a si se dá a liberdade de um modo também imediato nas formas seguintes: a) A posse, que é propriedade; aqui, a liberdade é essencialmente liberdade da vontade abstrata ou, em outros termos, de uma pessoa particular que só se relaciona consigo mesma; $b$ ) A pessoa que se diferencia de si se relaciona com outra pessoa e ambas só como proprietárias existem uma para a outra; a identidade delas, que existe em si (virtual), adquire a existência pelo trânsito da propriedade de uma para outra, com mútuo consentimento e permanência do comum direito. Assim se obtém o contrato; c) A vontade como diferenciada na relação consigo mesma, (à) não porque se relacione com outra pessoa, mas $(b)$ porque é em si mesma vontade particular que se opõe ao seu ser em si e para si, constitui a injustiça e o crime. ${ }^{18}$

${ }^{18}$ HEGEL, 1997. p. 41. 
Para o presente trabalho entende-se adequado pontuar as duas primeiras formas, pois entende-se que é justamente a relação entre pessoa a propriedade que permite a compreensão do que seja outro conceito importante, que é o conceito de coisa. Porém, antes de discutir referido conceito é interessante citar o seguinte:

41 - Deve a pessoa dar-se um domínio exterior para a sua liberdade a fim de existir como ideia. Porque nesta primeira determinação, ainda completamente abstrata, a pessoa é a vontade infinita em si e para si, tal coisa distinta dela, que pode constituir o domínio da sua liberdade, determina-se como o que é imediatamente diferente e separável. 42 - O que é imediatamente diferente do espírito livre, e considerado este como em si, é a extrinsecidade em geral: uma coisa, qualquer coisa de não livre, sem personalidade e sem direito. Nota - A coisa, como a objetividade, tem duas significações opostas: por um lado, quando se diz "é a mesma coisa, trata-se da coisa e não da pessoa", isso significa algo substancial; por outro lado, porém, a coisa aparece em relação à pessoa (não no sentido de sujeito particular) como o contrário do que é substancial, como aquilo que por definição é apenas extrinsecidade. O que é extrínseco para o espírito livre (que se deve distinguir da simples consciência), o é de uma maneira absoluta, em si e para si, tal como a definição conceitual da natureza é a de ser a extrinsecidade em si mesma. ${ }^{19}$

Diante desse fragmento cabe uma abordagem em torno da extrinsecidade. Esse processo de exteriorização faz com a propriedade seja valorizada, pois é por intermédio dela que essa exteriorização é percebida e neste processo aquele que não consegue exteriorizar-se por meio da coisa não será considerado pessoa, ou seja, humano capaz de expressar-se na propriedade.

Ocorre, que essa propriedade como expressão da pessoa não é uma condição alcançada por todos, ou seja, nem todos os humanos serão bem aventurados neste processo e isso fará fatalmente com que aqueles que se alçam a condição de pessoa iniciem a dominação dos demais por meio da propriedade que é entendida como a externalização do indivíduo.

Dessa maneira, a propriedade passa a ser elemento diferenciador entre um indivíduo e outro e justamente por isso é posta no centro deste processo de dominação do proprietário sobre o não proprietário. E dessa forma chega-se a um ponto crucial que é justamente o de que o Estado surge para proteger a propriedade que é entendida como a expressão externa da pessoa.

Logo, pode-se concluir que o Estado protege uma exceção que é a propriedade, pois como já analisado a propriedade é elemento extrínseco do ser humano, elemento este que não

${ }^{19}$ Ibidem. p. 44. 
é alcançado por todos. E essa proteção estatal é feita pelo ordenamento jurídico, ou seja, o direito, a lei, e demais formas de regulamentos, enfim pelo mundo do dever ser. Portanto, sem a propriedade não haveria necessidade de direito, ou melhor, talvez o direito sequer tivesse surgido neste modelo conhecido.

Feita essa ponderação é importante uma análise em torno da expressão Estado de exceção, ou seja, lançou-se a ideia de Estado se funda em uma exceção que é a propriedade e por conseguinte as expressões de Estado e exceção apresentam uma similitude bastante consistente.

Neste sentido, frequente são as análises e discussões em torno do Estado de Exceção, seu surgimento não é recente, mas talvez o seu conceito é que tenha sido aprimorado, ou se desenvolvido de modo mais claro atualmente.

Daí uma questão central. Se a propriedade é algo escasso como pode algo que surgiu da propriedade ser abundante? É refletir sobre o fato de que o direito é exceção porque surge de uma exceção, a propriedade. Logo, o direito assim como sua fonte (a propriedade) é exceção.

Em essência o direito é escasso, mas devido a uma construção histórica o homem irá interpreta-lo de dois modos: o primeiro deles é como liberdade para os proprietários, e o segundo é como ordem de negação, uma espécie de obrigação de não fazer, para os não proprietários.

Interessante é analisar que Estado e Direito também se criam e se complementam na medida em que o direito produzido pelo Estado serve de justificação para o poder estatal e ao mesmo tempo em que regulamenta a relação entre os proprietários e os não proprietários. Nesse sentido chega-se a uma reflexão de que Estado e direito se fundem, constroem-se mutuamente, logo, o termo Estado de direito é em essência Estado de exceção.

Após do delineamento desse raciocínio explica-se o modo como se cunhou o termo usado no início do tópico, a saber: Exceção + Estado = Extado. Este é o conceito que expressa ao mesmo tempo uma fase da sociedade capitalista.

E com essa compreensão que se parte para o entendimento do que seja o Estado de Exceção e para isso um ir-se-á apoiar na obra de Giorgio Agamben ${ }^{20}$. O estado de exceção fica no limite entre a política e o direito. ${ }^{21}$

${ }^{20}$ AGAMBEN, 2004.

Rev. de Teorias da Democracia e Direitos Políticos | e-ISSN: 2525-9660 | Goiânia| v. 5 | n. 1 | p. 63-81| Jan/Jun. 2019 
Estar no limite entre a política e o direito entende-se aqui como um lugar, ou posição, de algo que esteja entre o mundo real representado pela política (ser) e o mundo virtual representado pelo direito (dever ser). De maneira que para Giorgio Agamben o estado de exceção apresenta-se como a forma legal do que não pode ter forma legal. ${ }^{22}$

O estado de exceção volta-se para o espaço interno do Estado, para seus elementos constituidores povo, território e poder. E é o que se define como guerra civil legal e este termo/definição é contraditório, pois para Thomas Hobbes ${ }^{23}$ a guerra civil é a morte do Leviatã.

Na linha do que Giorgio Agamben chamou de guerra civil legal cite-se Adolf Hitler que promulgou o "Decreto para a proteção do povo e do Estado" que suspendeu direitos relativos às liberdades

O decreto nunca foi revogado, de modo que todo o Terceiro Reich pode ser considerado, do ponto de vista jurídico, como um estado de exceção que durou doze anos. O totalitarismo moderno pode ser definido, nesse sentido, como a instauração, por meio do estado de exceção, de uma guerra civil legal que permite a eliminação física não só dos adversários políticos, mas também de categorias inteiras de cidadãos que, por qualquer razão, pareçam não integráveis ao sistema político. Desde então, a criação voluntária de um estado de emergência permanente (ainda que, eventualmente, não declarado no sentido técnico) tornou-se uma das práticas essenciais dos Estados contemporâneos, inclusive dos chamados democráticos. Diante do incessante avanço do que foi definido como uma "guerra civil mundial", o estado de exceção tende cada vez mais a se apresentar como o paradigma de governo dominante na política contemporânea. Esse deslocamento de uma medida provisória e excepcional para uma técnica de governo ameaça transformar radicalmente - e, de fato, já transformou de modo muito perceptível - a estrutura e o sentido da distinção tradicional entre os diversos tipos de constituição. O estado de exceção apresenta-se nessa perspectiva, como um patamar de indeterminação entre democracia e absolutismo. ${ }^{24}$

Percebe-se que o autor se empenha em estabelecer que o estado de exceção situa-se em um limbo, um espaço entre o direito e a política, ou entre a democracia e o absolutismo. Porém, confirmar esse raciocínio nada mais é que trabalhar intelectualmente para fundamentar o que o próprio Giorgio Agamben definiu como "dar forma legal ao que não tem forma legal".

${ }^{21}$ Ibidem, p. 11.

${ }^{22}$ Ibidem, p. 12.

${ }^{23}$ HOBBES, Thomas. Leviatan: O la matéria, forma y poder de uma república eclesiástica y civil. Traducción Manuel Sánchez Sarto. Fondo de Cultura Econômica. México. 1998.

${ }^{24}$ AGAMBEN, 2004. p. 12/13. 
O que se propõe aqui é que se faça um trabalho intelectual, mas não neste sentido de atribuir juridicidade ao que não tem forma legal e sim para explicitar que estado de exceção é absolutismo, é política e não direito, é o Leviatã forte e altivo, enfim é o próprio Estado sem nenhum pudor de agir dentro de sua essência de Extado. Percebe-se ainda é a compreensão de que estado de exceção é na verdade uma técnica de governo que torna-se permanente no mundo contemporâneo.

\section{Estado e Democracia: uma análise sobre o Brasil.}

Neste momento não se pode deixar de analisar de modo mais detido a essência da democracia. Dessa maneira pondera Giorgio Agamben:

O estado de exceção em que a Alemanha se encontrou sob a presidência de
Hindenburg foi justificado por Schimitt no plano constitucional a partir da ideia de
que o presidente agia como 'guardião da constituição' (Schimitt, 1931); mas o fim
da República de Weimar mostra, ao contrário e de modo claro, que uma 'democracia
protegida' não é uma democracia e que o paradigma da ditadura constitucional
funciona sobretudo como uma fase de transição que leva fatalmente à instauração de
um regime totalitário. ${ }^{25}$

A citação apresentou o entendimento de que democracia não pode ter tutor, a democracia não pode ter um protetor, isso não se coaduna com sua característica formal. Essa citação é fundamental para que se possa adentrar ao caso da democracia no Brasil.

Importante ainda é fazer uma ponderação, necessária, neste momento. Ao analisarmos aqui aspectos da democracia no Brasil é importante que não se perca de vista que a democracia é um subterfúgio para camuflar/esconder em dado momento o constante estado de exceção (Extado).

O Brasil como se sabe foi colonizado no início do século XVI e consequentemente está em uma fase menos avançada do capitalismo, ou seja, trata-se de um país periférico e consequentemente isto impacta de modo direto no tocante a efetividade do conceito de democracia brasileira.

Dessa maneira, a burguesia brasileira apresentará características peculiares de países periféricos e se de modo geral essa classe não precisará necessariamente refazer os mesmo caminhos da burguesia inglesa por exemplo.

${ }^{25}$ AGAMBEN, 2004. p. 29. 
Ocorre, que isso apresenta implicações internas e externas no que se refere ao modo como essa burguesia brasileira periférica se relacionará com as demais classes. É importante destacar que frente ao avanço de organizações populares, ainda que distantes de processos revolucionários, a solução encontrada foi a repressão política e policial direta, em especial através de dois períodos ditatoriais ${ }^{26}$.

Esses períodos representam em nossa história momentos em que o conceito de Extado esteve visível, perceptível. Esses momentos foram as ditaduras cujos processos se iniciam em 1937 e 1964.

O professor Florestan Fernandes apresentou uma análise sobre como a burguesia brasileira pautou suas ações na obra A revolução burguesa no Brasil, em especial destacamos o tópico Contra-revolução prolongada e "aceleração da história" 27.

Em tal texto Florestan Fernandes expõe o motivo do aparente êxito da burguesia brasileira nesse movimento que a levou, finalmente, a descobrir e a cumprir as tarefas e os papéis que lhe cabiam no contexto histórico global?

\begin{abstract}
As respostas a esta pergunta sublinham, com frequência, quatro fatores. As características demográficas, econômicas e sociais da sociedade brasileira, que tornam viável e fácil uma nova eclosão do industrialismo e a aceleração do crescimento econômico com colaboração externa; a assistência técnica, econômica e política intensiva das nações capitalistas hegemônicas e da 'comunidade internacional de negócios'; a forte identificação das forças armadas com os móveis econômicos, sociais e políticos das classes burguesas e sua contribuição prática decisiva na rearticulação do padrão compósito de dominação burguesa; a ambiguidade dos movimentos reformistas e nacionalistas de cunho democráticoburguês e a fraqueza do movimento socialista revolucionário, com forte penetração pequeno-burguesa e baixa participação popular ou operária. Esses fatores são, de fato, suficientes para 'explicar o que houve', mas eles fixam as respostas no plano morfológico das relações e conflitos de classe. É possível ir um pouco mais longe indagando-se porque afinal de contas, em determinado momento a burguesia brasileira realizou o seu movimento histórico de uma forma que é especificamente contra-revolucionária (em termos do padrão democrático-burguês 'clássico' de revolução nacional) e envolve uma ruptura com todo arsenal ideológico e utópico inerente às 'tradições republicanas' da mesma burguesia. ${ }^{28}$
\end{abstract}

A compreensão apresentado por Florestan Fernandes se mostra fundamental para a compreensão do conceito de Extado, ou seja, a democracia em nossa história é que se encaixa melhor na compreensão de momento atípico, ou de exceção. Para evitar alguma confusão é

\footnotetext{
${ }^{26}$ FONTES, Virgínia. Capitalismo, luta de classes e democracia no Brasil contemporâneo. In Carla Luciana Silva, Gilberto Grassi Calil e Marcio Antônio Both da Silva (orgs.), Ditaduras e democracias: estudos sobre poder, hegemonia e regimes políticos no Brasil (1945-2014). Porto Alegre: FCM Editora. 2014. p.238.

${ }^{27}$ FERNANDES, 1987.

${ }^{28}$ Ibidem, p. 310.
} 
importante repetir a compreensão de que a democracia é um subterfúgio cujo papel é apenas ofuscar o estado de exceção.

Ocorre que no Brasil a história mostra uma situação ainda mais complexa, pois sequer chegamos a gozar a democracia, ou seja, o Brasil como país periférico é uma demonstração importante de que o estado de exceção é a regra.

Ressalte-se que o presente trabalho procura demonstrar que o estado de exceção é a regra em todos os Estados, porém no Brasil o que se percebe é que sequer existiram períodos democráticos que pudessem ofuscar o padrão constante que é a exceção. E a burguesia brasileira tem papel decisivo nisso, pois por vezes reduziu seu papel a uma atuação contrarrevolucionária.

O processo de formação dessa burguesia brasileira, ou ao menos da sua forma de pensar é descrito da seguinte forma:

\begin{abstract}
As quatro décadas que se sucederam ao fim da Primeira Grande Guerra constituem o período nuclear de maturação histórica da burguesia brasileira. Esse período não representa, como muitos acreditam, a 'época de formação' dessa burguesia (muito anterior como vimos); nem, como sustentam outros, ele corresponde à 'época de crise da oligarquia' (pois esta crise se desenrolou, no Brasil, como uma recomposição das estruturas econômicas, sociais e políticas herdadas do passado, pela qual os estratos sociais de origem oligárquica, antiga ou recente, foram reabsorvidos pela organização da sociedade de classes em constituição e expansão). Não ocorreu, portanto, um verdadeiro deslocamento da 'velha classe' ou das 'velhas classes' dominantes, por 'novas classes' dominantes, de formação hodierna. Mas um fenômeno muito mais amplo e (embora não pareça) mais dramático: a coalescência estrutural dos vários estratos sociais e das várias categorias econômicas que formavam as 'classes possuidoras', crescentemente identificadas com uma concepção burguesa do mundo e com um estilo burguês de vida, graças à rápida e contínua aceleração da revolução urbano-comercial e, em seguida, à industrialização. Os estamentos dominantes do 'antigo regime' imergem e desaparecem, assim, nas estruturas da ordem social competitiva e da sociedade de classes em constituição ou em expansão (conforme a região ou a localidade do país que se considere). Contudo, as oligarquias, 'tradicionais' ou 'modernas' sofrem muito pouco com isso e a crise de reabsorção pela qual elas passam, não possui o mesmo significado histórico que o aparecimento da burguesia como uma categoria histórico-social e uma comunidade política. ${ }^{29}$
\end{abstract}

Essa característica da burguesia brasileira talvez seja reflexo da condição de país periférico, pois se o desenvolvimento capitalista se dá de forma desigual e combinada aqueles países que iniciaram esse desenvolvimento primeiramente estão em fases mais desenvolvidas e dessa forma podem controlar os rumos do desenvolvimento capitalista dos países cujo capitalismo tem pouco tempo de maturação.

${ }^{29}$ FERNANDES, 1987. p. 311. 
Florestan Fernandes analisou que as para "governar seu mundo", as classes burguesas deviam começar por conhecê-lo melhor e por introduzir a racionalidade burguesa na compreensão de seus papéis históricos sob o capitalismo dependente. Essa aprendizagem realizou-se por etapas e por três vias diversas, todas frustradoras.$^{30}$ Cite-se:

Primeiro, através da descoberta de que não iríamos 'repetir a história'. A grande esperança republicana de que se faria a revolução industrial de modo autônomo e segundo o modelo de desenvolvimento econômico inerente ao capitalismo competitivo, esboroa-se por completo no limiar mesmo da industrialização intensiva. Quando isso ficou patente também se evidenciou que a concretização de uma democracia burguesa plena não era uma 'questão de tempo' nem de 'gradualismo político'. Os cálculos infundados e as expectativas erradas tinham de ser revistos. Assim, a burguesia brasileira aprendeu de um golpe, que a história não é autogerminadora; e que ela não corrige os erros dos homens, nasçam eles de ambições exageradas ou de fantasias medíocres ${ }^{31}$.

Essa primeira via pode ser compreendida retomando o fato de que o desenvolvimento capitalista é desigual e combinado, ou seja, temos os países hegemônicos que são protagonistas no que tange as fases do capitalismo em que se encontram, fases avançadas, já no que se refere ao fato de este capitalismo estar combinado é cite-se que estes países hegemônicos controlam, articulam, o seu desenvolvimento com o desenvolvimento dos países periféricos, logo, de modo combinado os países hegemônicos autorizam, permitem, que países periféricos como o Brasil avancem no seu desenvolvimento capitalista. Eventuais mudança de fase se dão de modo combinado. Continuando temos:

Segundo, através de entrechoques alimentados por antagonismos intraclasses, ou seja, por interesses e aspirações divergentes de classes ou estratos de classe burgueses. Ignorando os limites de seus papéis históricos, em diferentes momentos, setores civis ou militares e civis-militares, da alta e média burguesia, lançaram-se a aventuras tidas como 'nacionalistas', 'democráticas', e 'revolucionárias' - e de fato elas sofriam essa elaboração intencional; e seriam isso mesmo, se fosse possível transformar, primeiro as bases dependentes das relações de produção e de mercado. Todavia, as classes burguesas que lutavam por causas tão amplas não tinham coragem de romper com a dominação imperialista e com os liames que as prendiam às várias formas de subdesenvolvimento interno. Em consequência, patronizavam uma variedade especial de 'populismo', a demagogia populista, agravando os conflitos de classe sem aumentar, com isso, o espaço político democrático, reformista e nacionalista da ordem burguesa existente. Estas foram, no entanto, as experiências que acordaram a burguesia brasileira para a sua verdadeira condição, ensinando-a a não procurar vantagens relativas para estratos burgueses isolados, à custa de sua própria segurança coletiva e da estabilidade da dominação burguesa. ${ }^{32}$

${ }^{30}$ FERNANDES, 1987. p. 313.

${ }^{31}$ Ibidem, p. 313.

${ }^{32}$ Ibidem, p. 314. 
Afinal de contas a burguesia só conseguiu promover sua revolução na medida em que foi capaz de implementar luta política por liberdade, ou seja, sem que a burguesia estivesse livre seu protagonismo histórico seria impossível. Porém, a burguesia brasileira não foi capaz de romper com as amarras que a prendiam, pelo contrário optou por caminhos muito mais próximos de uma tutela vinda de países hegemônicos para preservar seu local de privilégio frente ao restante da sociedade.

Terceiro, através da exposição de elites das classes burguesas a influências socializadoras externas e de manipulações diretas de problemas internos por meio de controles desencadeados e/ou orientados a partir de fora. O âmbito da dominação imperialista aprofunda-se e alarga-se com a passagem do capitalismo competitivo para o capitalismo monopolista. Não existem neste último, fronteiras ao controle societário externo, o que permite falar em um imperialismo total. As experiências, nessa esfera, são bem conhecidas. Há os grupos, extraídos de várias categorias profissionais, civis e militares, que foram deslocados para o exterior e sofreram completa reciclagem (ideológica e utópica), graças a programas especiais de 'treinamento', de 'preparação técnica especializada' ou de doutrinação. Há os programas de comunicação em massa, através do rádio, televisão, imprensa e mesmo da educação escolarizada e os programas de assistência técnica (saúde, cooperação militar defesa e segurança pública, cooperação econômica, cooperação educacional etc.), que criam redes articuladas de 'modernização dirigida'. Há, por fim, programas de instituições mundiais e de Governo a Governo que recobrem essas outras áreas, todos difundindo uma filosofia desenvolvimentista própria. Por aqui, os extratos burgueses aprenderam a mudar a qualidade de suas percepções e explicações do mundo, procurando ajustar-se a 'avaliações pragmáticas', que representam o subdesenvolvimento como um 'fato natural' autocorrigível e estabelecem como ideal básico o princípio, irradiado a partir dos Estados Unidos, do 'desenvolvimento com segurança'. Dava-se, assim, o último salto na limpeza do sótão. A burguesia brasileira encontrava novos elos de 'modernização', descartandose de suas quinquilharias históricas libertárias, de origem europeia, substituídas por convicções bem mais prosaicas, mas que ajustavam seus papéis à 'unidade do hemisfério', à interdependência das nações democráticas' e à 'defesa da civilização ocidental'. 33

A dependência da burguesia brasileira desse apoio externo é exemplo cristalino de que o processo descrito de que o capitalismo se desenvolve de modo desigual e combinado, permitindo que a burguesia brasileira, grosso modo, optasse por delegar seu processo histórico aos países hegemônicos. Essas três vias apontadas por Florestan Fernandes produziram cenários históricos no Brasil cujos impactos existiriam por longo tempo.

Identificamos um desses impactos no golpe de 2016, pois analisando percebe-se que o maior período de "formalidade democrática" da história deste país foi de 1988 a 2016 e tal

${ }^{33}$ FERNANDES, 1987. p. 315. 
período foi interrompido por um golpe de estado que culminou com a queda da Presidente Dilma Vana Roussef após quatorze anos de governo do Partido dos Trabalhadores - PT.

Mas afinal porque derrubar o PT que nunca foi problema para o acúmulo capitalista? Bancos, agronegócio, especuladores, etc. todos tiveram taxas de lucro astronômicas no período em que o Brasil foi presidido por Luíz Inácio Lula da Silva e Dilma Vana Roussef. A única resposta plausível é o fato de que a burguesia brasileira atuou no sentido da Contrarrevolução prolongada como definiu Florestan Fernandes.

Dessa forma temos o seguinte:

As burguesias da periferia sofrem, desse modo, uma oscilação ideológica e utópica,
condicionada e orientada a partir de fora. De classes patronizadoras da revolução
democrático-burguesa nacional passam, a conceber-se como pilares da ordem
mundial do capitalismo, da 'democracia' e da 'civilização cristã'. Essa reviravolta
ideológica e utópica, quanto às suas repercussões no plano interno, não só aumenta o
grau de alienação filosófica, histórica e política da burguesia perante os problemas
nacionais e sua solução. Ela fortalece a insensibilidade diante deles, na medida em
que não perturbem o desenvolvimento capitalista interno nem o 'equilíbrio do
sistema capitalista mundial', ou, ainda, na medida em que sejam uteis para a
intensificação da acumulação capitalista. E suscita enorme indulgência para com
atitudes e comportamentos que se chocam, precisamente, com os mores da
democracia e da civilização cristã, o que significa que, indiretamente, ela amplifica o
espaço psicológico, cultural e político para o florescimento de um padrão de
liberdade de classe que é extremamente egoístico e irresponsável.

Processo real de ódio às classes baixas, ou seja, é uma burguesia que olha pra baixo antes mesmo de ter derrubado o poder central, isso é fruto da subserviência introduzida no Brasil pelos países Hegemônicos. A história de nossa burguesia permite concluir que no Brasil o Extado é muito mais evidente do que em países hegemônicos, pois nossa burguesia se moldou patrimonialista, escravista, e atuou ao longo da história sempre fundada na repressão das massas, às vezes mais repressão, e às vezes menos repressão.

No fundo, a referida reviravolta confere novos fundamentos psicológicos, morais e políticos ao enrijecimento da dominação burguesa e à sua transfiguração numa força social especificamente autoritária e totalitária. É aqui, e não numa suposta deterioração do liberalismo nem numa presumível exacerbação do mandonismo tradicionalista, que se devem procurar as raízes psicossociais e históricas da mudança do horizonte cultural das classes e estratos de classes burgueses. Essa mudança levou, gradualmente, nas últimas quatro décadas, a uma nova filosofia política e a ações de classes que puseram em primeiro plano o privilegiamento as situação de interesses da burguesia como um todo. Ela serviu, pois como de fundamento para uma solidariedade de classes que deixou de ser 'democrática' ou, mesmo, 'autoritária', para tornar-se abertamente 'totalitária' e contra-revolucionária, em suma, o fermento de uma ditadura de classe preventiva. ${ }^{35}$

\footnotetext{
${ }^{34}$ FERNANDES, 1987. p. 316.

${ }^{35}$ Ibidem, p. 317.
} 
A burguesia brasileira tornou-se uma classe inercial, ou seja, está parada e portanto permanecerá parada atuando contra tudo e todos que possam ameaçar sua posição/condição de inércia. Absolutamente importante para o raciocínio desenvolvido no presente trabalho é a definição do autor que define a burguesia brasileira como abertamente totalitária e elemento central para a uma ditadura de classe preventiva.

Não existe conceito melhor que o de Florestan Fernandes para expressar o que defendemos até aqui, pois no Brasil essa ditadura de classe preventiva reverberou e reverbera como o estado de exceção que tornou-se regra, que definimos como Extado. Neste contexto a burguesia brasileira se estabeleceu e permanece inercialmente imóvel graças a sua capacidade de implementar no Brasil esta estado de ditadura preventiva e portanto permanente.

\section{CONCLUSÃO}

Após as análises e pesquisas a conclusão em que se chega é que o Brasil como país de capitalismo tardio, ou de capitalismo periférico, sofreu um processo de dependência no que tange ao seu processo de desenvolvimento econômico.

Isto porque o desenvolvimento capitalista é controlado pelos países hegemônicos, ou seja, ele se dá de modo desigual e combinado, pois no cenário mundial os países ditos hegemônicos como Inglaterra e Estados Unidos se desenvolveram primeiro por isso encontram-se em fase mais avançada, ao passo que os países periféricos como o Brasil sempre estarão em fase inferior e a sua progressão é combinada com o avanço dos países hegemônicos.

Isso gera uma dependência e no caso do Brasil esse processo fez com que a burguesia nacional se forjasse dentro dessa estrutura e por isso não rompeu com o patrimonialismo e com o escravismo. Um Estado capitalista que não tem liberdade para se desenvolver produz na burguesia uma cultura voltada não na luta pela liberdade, mas uma luta para não perder seu espaço de recepção das vantagens vindas dos países hegemônicos.

Isso desenvolveu em nossa burguesia uma cultura de ódio a todo processo que pudesse lhe retirar do local de vantagens, é uma burguesia que não luta pela revolução, ela luta para que as coisas permaneçam como estão. E neste sentido a burguesia brasileira historicamente 
trabalhou para evitar a revolução por meio de uma contrarrevolução prolongada conforme explicou Florestan Fernandes.

Ocorre, que essa contrarrevolução prolongada nada mais é que o estado de exceção constante no Brasil desde o surgimento do Estado brasileiro. Isso faz do Brasil um local em que se pode constatar perfeitamente que o Extado (Exceção + Estado) é uma constante. Isto fica mais evidente no Brasil pelo fato de termos um agravante que é o fato de, ao contrário dos países hegemônicos, que nunca tivemos uma democracia efetiva.

Lembrando que a democracia foi apresentada neste texto como um subterfúgio para ofuscar o estado de exceção (Extado) e nos países periféricos como o Brasil a contrarrevolução prolongada, ou estado de exceção, ou Extado, sequer temos a democracia para ofuscar o estado de exceção.

\section{REFERÊNCIAS}

AGAMBEN, Giorgio. Estado de exceção. Tradução de Iraci D. Poleti. São Paulo: Boitempo, 2004.

ARENDT, Hannah. A condição humana. Tradução Roberto raposo, revisão técnica: Adriano Correia. 11 ed. Rio de Janeiro: Forense Universitária, 2010.

CANETTI, Elias. Massa e poder. Trad. Sergio Tallaroni. São Paulo: Companhia das Letras, 1995.

CARDOSO, Fernando Henrique. A construção da democracia: estudos sobre a política brasileira. São Paulo: Siciliano, 1993.

CHEVAllieR, Jacques. O Estado Pós-Moderno = L'État post-moderne / Jacques Chevallier; prefácio de Marçal Justen Filho. Belo Horizonte: Fórum, 2009.

As grandes obras políticas de Maquiavel a nossos dias. Prefácio André Siegfried. Tradução de Lydia Christina. 6 ed. Rio de Janeiro: Agir, 1993. 
FERNANDES, Florestan. A revolução burguesa no Brasil; ensaio de interpretação sociológica. 3 ed. Rio de Janeiro: Guanabara, 1987.

FONTES, Virgínia. Capitalismo, luta de classes e democracia no Brasil contemporâneo. In Carla Luciana Silva, Gilberto Grassi Calil e Marcio Antônio Both da Silva (orgs.), Ditaduras e democracias: estudos sobre poder, hegemonia e regimes políticos no Brasil (1945-2014). Porto Alegre: FCM Editora. 2014.

HEGEL, Georg Wilíelm Friedrich, 1770-1831. Princípios da filosofia do direito / G.W.F. Hegel; tradução Orlando Vitorino. - São Paulo: Martins Fontes, 1997.

HOBBES, Thomas. Leviatan: 0 la matéria, forma y poder de uma república eclesiástica y civil. Traducción Manuel Sánchez Sarto. Fondo de Cultura Econômica. México. 1998.

JOUVENEL, Bertrand de, 1903 -1987. Bertrand de Jouvenel des Ursins. O poder: história natural de seu crescimento. Tradução Paulo Neves. 1. ed. São Paulo: Peixoto Neto. 1998.

LENINE, Vladimir Ilitch. O Estado e a Revolução. Agosto-Setembro 1917. Disponível em: < http://pcb.org.br/portal/docs/oestadoearevolucao.pdf > Acesso em: 06 de AGO. de 2018.

MACHIAVELLI, Niccolò, 1469-1527. O príncipe: com notas de Napoleão Bonaparte / Maquiavel; tradução de J. Cretella Jr. e Agnes Cretella. 3 ed. rev. da tradução - São Paulo: Editora Revista dos Tribunais, 2003.

MASCARO, Alysson Leandro. Estado e forma política. São Paulo: Boitempo. 2013.

MAUS, Ingeborg. O Direito e a Política: teoria da democracia. Tradução Elisete Antoniuk e Martonio Mont'Alverne Barreto Lima. Coordenador e supervisor Luiz Moreira. Belo Horizonte: Del Rey, 2009. 
MENDES, Gilmar Ferreira. Curso de Direito Constitucional / Gilmar Ferreira Mendes, Inocêncio Mártires Coelho, Paulo Gustavo Gonet Branco. São Paulo: Saraiva, 2007.

MÉSZÁROS, István. A montanha que devemos conquistar: reflexões acerca do Estado. Tradução Maria Izabel Lagoa. 1 ed. São Paulo: Boitempo, 2015.

PARKER, Robert Alexander Clarke. História da II Guerra Mundial. São Paulo: Edições 70, 2006.

PASSOS, Izabel C. Friche. Poder, normalização e violência: incursões foucaultianas para a atualidade. 2 ed. Belo Horizonte: Autêntica Editora, 2013.

PEIXOTO, Rodrigo Corrêa Diniz. Memória social da Guerrilha do Araguaia e da guerra que veio depois. Boletim do Museu Paraense Emílio Goeldi. Ciências Humanas, v. 6, n. 3, p. 479-499, set.-dez. 2011.

PUGLIESI, Marcio. Teoria do Direito. 2 ed. São Paulo: Saraiva, 2009.

ROUSSEAU, Jean-Jacques, 1712-1778. Discurso sobre a origem e os fundamentos da Desigualdade entre os homens. Introdução de João Carlos Brum Torres. Tradução de Paulo Neves. Porto Alegre: L\&PM, 2009. 